University of Montana

ScholarWorks at University of Montana

\title{
Probable causes of increasing brucellosis in free-ranging elk of the Greater Yellowstone Ecosystem
}

P. C. Cross

E. K. Cole

A. P. Dobson

W. H. Edwards

K. L. Hamlin

See next page for additional authors

Follow this and additional works at: https://scholarworks.umt.edu/biosci_pubs

Part of the Biology Commons

Let us know how access to this document benefits you.

\section{Recommended Citation}

Cross, P. C.; Cole, E. K.; Dobson, A. P.; Edwards, W. H.; Hamlin, K. L.; Luikart, Gordon; Middleton, A. D.; Scurlock, B. M.; and White, P. J., "Probable causes of increasing brucellosis in free-ranging elk of the Greater Yellowstone Ecosystem" (2010). Biological Sciences Faculty Publications. 360.

https://scholarworks.umt.edu/biosci_pubs/360

This Article is brought to you for free and open access by the Biological Sciences at ScholarWorks at University of Montana. It has been accepted for inclusion in Biological Sciences Faculty Publications by an authorized administrator of ScholarWorks at University of Montana. For more information, please contact scholarworks@mso.umt.edu. 


\section{Authors}

P. C. Cross, E. K. Cole, A. P. Dobson, W. H. Edwards, K. L. Hamlin, Gordon Luikart, A. D. Middleton, B. M. Scurlock, and P. J. White 


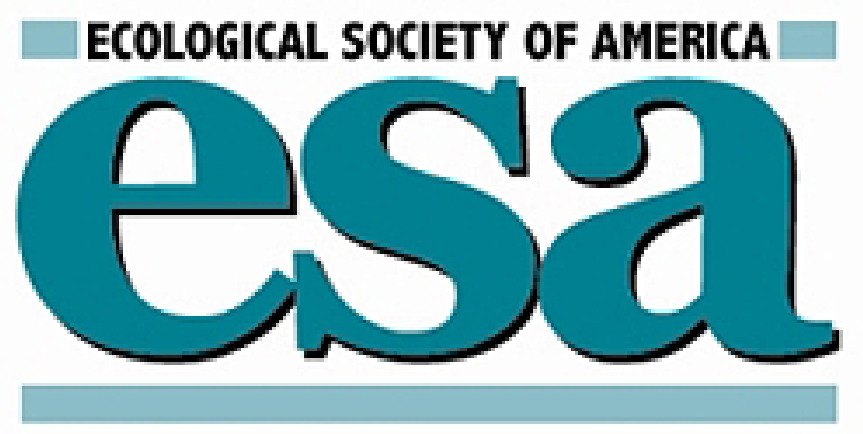

Probable causes of increasing brucellosis in free-ranging elk of the Greater Yellowstone Ecosystem

Author(s): P. C. Cross, E. K. Cole, A. P. Dobson, W. H. Edwards, K. L. Hamlin, G. Luikart, A. D. Middleton, B. M. Scurlock and P. J. White

Source: Ecological Applications, Vol. 20, No. 1 (January 2010), pp. 278-288

Published by: Ecological Society of America

Stable URL: http://www.jstor.org/stable/27797805

Accessed: $13 / 12 / 2013$ 12:49

Your use of the JSTOR archive indicates your acceptance of the Terms \& Conditions of Use, available at http://www.jstor.org/page/info/about/policies/terms.jsp

JSTOR is a not-for-profit service that helps scholars, researchers, and students discover, use, and build upon a wide range of content in a trusted digital archive. We use information technology and tools to increase productivity and facilitate new forms of scholarship. For more information about JSTOR, please contact support@jstor.org. 


\title{
Probable causes of increasing brucellosis in free-ranging elk of the Greater Yellowstone Ecosystem
}

\author{
P. C. Cross, ${ }^{1,10}$ E. K. Cole, ${ }^{2}$ A. P. Dobson, ${ }^{3}$ W. H. Edwards, ${ }^{4}$ K. L. Hamlin, ${ }^{5}$ G. Luikart, ${ }^{6}$ A. D. Middleton, ${ }^{7}$ \\ B. M. SCURlock, ${ }^{8}$ AND P. J. White ${ }^{9}$ \\ ${ }^{1}$ U.S. Geological Survey, Northern Rocky Mountain Science Center, 229 AJM Johnson Hall, Bozeman, Montana 59717 USA \\ ${ }^{2}$ U.S. Fish and Wildlife Service, National Elk Refuge, P.O. Box 510, Jackson, Wyoming 83001 USA \\ ${ }^{3}$ Princeton University, 224 Guyot Hall, Princeton, New Jersey 08544 USA \\ ${ }^{4}$ Wyoming Game and Fish Department, 1174 Snowy Range Road, Laramie, Wyoming 82070 USA \\ ${ }^{5}$ Montana Fish, Wildlife, and Parks, 1400 S. 19 th Avenue, Bozeman, Montana 59718 USA \\ ${ }^{6}$ Centro de Investigacao em Biodiversidade e Recursos Geneticos, University of Portugal, Vairão, Portugal; and \\ Division of Biological Sciences, Health Sciences Building, Room 105, University of Montana, Missoula, Montana 59812 USA \\ ${ }^{7}$ Cooperative Fish and Wildlife Research Unit and Program in Ecology, 1000 E. University Avenue, University of Wyoming, \\ Laramie, Wyoming 82071 USA \\ ${ }^{8}$ Wyoming Game and Fish Department, P.O. Box 850, Pinedale, Wyoming 82941 USA \\ ${ }^{9}$ National Park Service, P.O. Box 168, Yellowstone National Park, Wyoming 82190 USA
}

\begin{abstract}
While many wildlife species are threatened, some populations have recovered from previous overexploitation, and data linking these population increases with disease dynamics are limited. We present data suggesting that free-ranging elk (Cervus elaphus) are a maintenance host for Brucella abortus in new areas of the Greater Yellowstone Ecosystem (GYE). Brucellosis seroprevalence in free-ranging elk increased from 0-7\% in 1991-1992 to 8 $20 \%$ in 2006-2007 in four of six herd units around the GYE. These levels of brucellosis are comparable to some herd units where elk are artificially aggregated on supplemental feeding grounds. There are several possible mechanisms for this increase that we evaluated using statistical and population modeling approaches. Simulations of an age-structured population model suggest that the observed levels of seroprevalence are unlikely to be sustained by dispersal from supplemental feeding areas with relatively high seroprevalence or an older age structure. Increases in brucellosis seroprevalence and the total elk population size in areas with feeding grounds have not been statistically detectable. Meanwhile, the rate of seroprevalence increase outside the feeding grounds was related to the population size and density of each herd unit. Therefore, the data suggest that enhanced elk-to-elk transmission in free-ranging populations may be occurring due to larger winter elk aggregations. Elk populations inside and outside of the GYE that traditionally did not maintain brucellosis may now be at risk due to recent population increases. In particular, some neighboring populations of Montana elk were 5-9 times larger in 2007 than in the 1970s, with some aggregations comparable to the Wyoming feeding-ground populations. Addressing the unintended consequences of these increasing populations is complicated by limited hunter access to private lands, which places many ungulate populations out of administrative control. Agency-landowner hunting access partnerships and the protection of large predators are two management strategies that may be used to target high ungulate densities in private refuges and reduce the current and future burden of disease.
\end{abstract}

Key words: Brucella abortus; brucellosis; Cervus elaphus; disease reservoir; free-ranging elk; Greater Yellowstone Ecosystem; host density; wildlife disease.

\section{INTRODUCTION}

Wildlife managers employ a number of strategies (e.g., artificial feeding, insertion of waterholes, release of fish stocks, hunting regulations, and predator control) that affect the aggregation patterns of target and non-target species. As an unintended consequence, parasites may benefit from increased host aggregation (McCallum et al. 2001, Lloyd-Smith et al. 2005, Cross et al. 2007).

Manuscript received 6 November 2008; revised 7 April 2009; accepted 6 May 2009. Corresponding Editor: N. T. Hobbs.

${ }^{10}$ E-mail: pcross@usgs.gov
Although a number of pathogen issues have been linked to overabundant game species in Europe (Gortázar et al. 2006), few examples exist in North America. In this study, we investigate how recent changes in the elk populations of the Greater Yellowstone Ecosystem (GYE) may be altering the dynamics of Brucella abortus, the pathogen that causes brucellosis.

Brucellosis is a chronic bacterial disease of livestock and wildlife and is among the most common zoonotic infections worldwide (Godfroid and Kasbohrer 2002, Pappas et al. 2006). In the GYE brucellosis was probably introduced from cattle to bison prior to 1917 
(Meagher and Meyer 1994). Brucella abortus causes abortions and is transmitted within and among wildlife and livestock when individuals investigate or feed near infected fetuses, placentas, or birthing fluids (Cheyille et al. 1998). Bulls are considered relatively unimportant to disease dynamics because several studies have failed to document sexual transmission from males to females in either cattle or bison (Lubbenhusin and Fitch 1926, King 1940, Thomsen 1943, Bendixen and Blom 1947, Robison 1994). Another mode of transmission is through milk as infected females nurse their calves (Cheville et al. 1998).

The entire United States cattle population was declared brucellosis free in February 2008, after 74 years of an eradication program (U.S. Department of Agriculture 2008). The excitement was short lived, however, because later in the year cattle infections were found in both Montana and Wyoming. Bison in Yellowstone National Park (YNP) tend to have high seroprevalence, roughly 50\% (Meyer and Meagher 1995), and to prevent the spread of brucellosis to cattle approximately $40 \%$ of the Yellowstone bison population was lethally removed in 2008. Data on the recent cattle infections are scarce, but elk are considered the most likely source due to the lack of contact between the infected cattle herds and bison. Elk are supplementally fed at 23 sites in Wyoming (Fig. 1) resulting in dense aggregations at the time when elk are likely to transmit the infection via abortion events in late winter and early spring. Historically, the brucellosis seroprevalence in elk was $10-30 \%$ at these feeding grounds, but only $2-3 \%$ in other elk populations around the GYE. Brucellosis is not known to persist in elk populations outside the GYE (Cross et al. 2007; Scurlock and Edwards, in press):

The elevated seroprevalence of brucellosis in elk of the southern GYE is almost certainly due to the presence of artificial feeding grounds that aggregate elk during the winter and spring and facilitate brucellosis transmission (Cross et al. 2007, Maichak et al. 2009). Twenty-one of the artificial feeding grounds and one "staging area" are maintained by the Wyoming Game and Fish Department (WGFD; see Plate 1). The National Elk Refuge is maintained by the U.S. Fish and Wildlife Service. Supplemental feeding began at some locations as early as 1910 to limit elk impacts on agricultural land and maintain elk populations despite shrinking native winter range (Smith 2001). Feedgrounds are intended to minimize contact between elk and cattle during winter, but they also increase the concentration of elk between November and April, and the transmission of Brucella abortus among elk is most likely between February and June (Roffe et al. 2004). The low seroprevalence of brucellosis, historically, in the unfed elk populations of the GYE has fostered an apparent consensus that $B$. abortus is not self-sustaining in elk populations that do not concentrate on artificial feeding grounds or share winter range with bison (Cheville et al. 1998). Elk were traditionally thought to be poor transmitters of brucel-

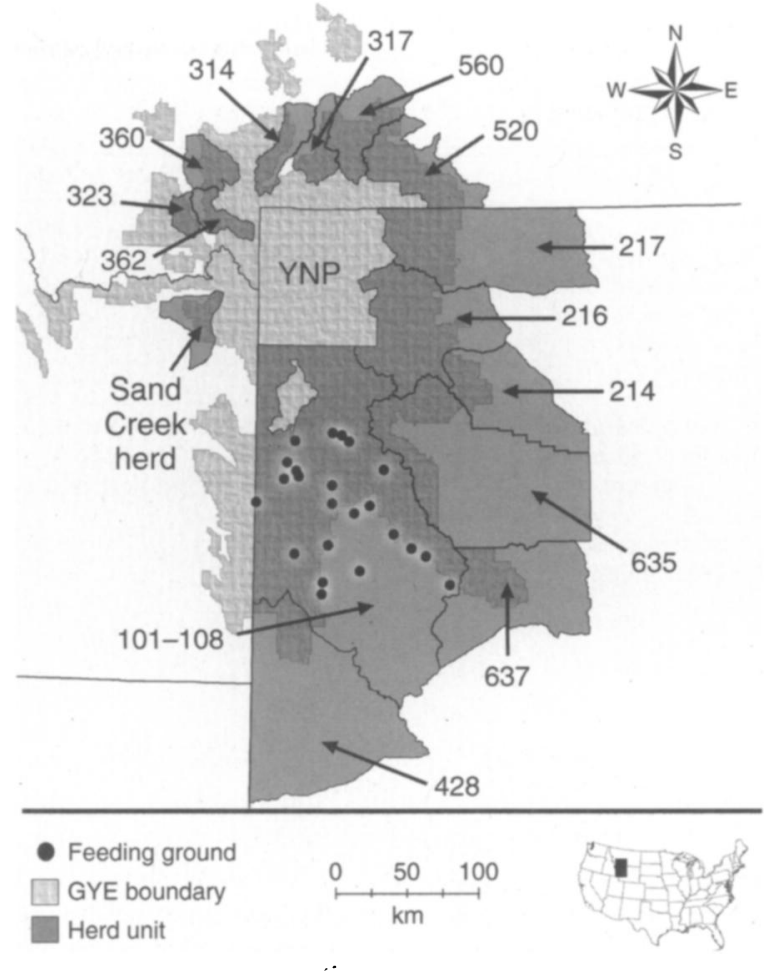

Fig. 1. Map of the study area showing the boundaries of the Wyoming and Montana, USA, elk (Cervus elaphus) herd units (gray polygons), supplemental elk feeding grounds (circles), Greater Yellowstone Ecosystem (GYE, light gray), and the area occupied by the Idaho Sand Creek elk herd.

losis because they tend to have their calves in seclusion (Cheville et al. 1998). This belief was also supported by the lack of brucellosis in elk populations outside the GYE, including those elk translocated from YNP.

In this study, we show that the seroprevalence of brucellosis has been increasing in several free-ranging elk populations of Wyoming. Using statistical and population modeling approaches we assess several plausible hypotheses behind these increases and discuss new research directions. We address four potential mechanisms for the increases in brucellosis: (1) enhanced elk-to-elk transmission due to population size and/or density; (2) increases in either population size or seroprevalence in elk herd units with supplemental feeding grounds; (3) dispersat of elk from feeding grounds to other regions; and (4) changes in age structure. We used seroprevalence and elk count data to address the first two hypotheses. Consistent data on age structure and dispersal were unavailable over the broad spatial and temporal scale necessary to address the latter two hypotheses. Therefore, we used an agestructured population model to assess theoretically how dispersal and shifting age structures may alter seroprevalence. We conclude by looking at some trends in elk counts and aggregation patterns in neighboring regions of Montana and discuss some potential implications. 
TABLE 1. Model comparison results of the logistic regressions of brucellosis serostatus of adult female elk (Cervus elaphus) from the Greater Yellowstone Ecosystem, using the hunter samples from 1991 to $2007(N=3384)$.

\begin{tabular}{lccc}
\hline \hline \multicolumn{1}{c}{ Model } & Parameters & QAIC & $\Delta$ QAIC \\
\hline Year: herd unit ${ }^{\dagger}$ & 7 & 553.5 & 0.0 \\
Year & 2 & 554.5 & 1.1 \\
Year + herd unit ${ }^{\dagger}$ & 7 & 556.1 & 2.6 \\
Year + herd unit & 12 & 562.0 & 8.6 \\
$\quad+$ year: herd unit§ & 1 & 580.8 & 27.3 \\
Intercept only & 1 & & \\
\hline
\end{tabular}

Notes: Models were corrected for overdispersion $(\hat{c}=1.8)$.

Feedground herd units (100-108) were excluded.

$\dagger$ Intercepts were constant among herd units, but year effects varied.

$\ddagger$ Intercepts varied by herd unit.

$\S$ Variable intercept and slope model.

\section{METHODS \\ Empirical data}

We used two data sets of elk brucellosis seroprevalence from Wyoming (Scurlock and Edwards, in press). The first data set consisted of 5533 elk blood samples collected by hunters from 1991 to 2007 in Wyoming herd units (HUs; Fig. 1). We restricted our analyses to the 3907. adult female elk to minimize the potential confounding effects of sex and age on the time trends. The second data set consisted of blood samples taken from 2070 adult female elk captured on the Wyoming supplemental feeding grounds from 1993 to 2008. Data collected from feeding-ground and non-feeding-ground herd units were analyzed separately. To determine brucellosis exposure we used the card test, plate agglutination, rivanol precipitation, fluorescence polarization assay using tubes, and complement fixation assays. A competitive ELISA (cELISA) was used to discriminate vaccine from field strain titers (Van Houten et al. 2003). Serological profiles were categorized using the U.S. Department of Agriculture (USDA) brucellosis eradication uniform methods and rules for cervids (Animal Plant Health Inspection Service 2003), with the exception that all suspect reactions were considered positive. These serological tests indicate whether or not an individual has been exposed, but not whether they are currently infected. More details on the collection procedures are available for the hunter-sampled data in Scurlock and Edwards, (in press); Cross et al. (2007) discuss the data collected on the feeding grounds.

We used logistic regression models of brucellosis status to assess whether the probability of an elk being seropositive increased over time for each herd unit (hereafter, HU). Herd units refer to broad regions of Wyoming where elk populations were believed to be relatively closed. We ran a suite of models that included HU and time effects in several different ways as explanatory variables (Table 1). We considered $\mathrm{HU}$ as a fixed effect. Our conclusions remained the same, however, when we ran models with $\mathrm{HU}$ as a random effect. Aggregating the data to counts of seropositives per year revealed overdispersion relative to the annual predictions of the saturated model $(\hat{c}=1.8$; Gelman and Hill 2007). So, we adjusted the standard errors and $P$ values using the dispersion option in $\mathrm{R}$ version 2.7.0 ( $\mathrm{R}$ Development Core Team 2005). We compared models using the quasi-Akaike's information criterion (QAIC; Burnham and Anderson 2002).

The role of population size in disease dynamics has been a topic of extensive research generally (e.g., McCallum et al. 2001, Lloyd-Smith et al. 2005) and specifically for brucellosis (Cross et al. 2007, Maichak et al. 2009). Due to the patchiness of the elk population and seroprevalence data, as well as the potentially complicated time lags between population size and seroprevalence, we focused on estimating how seroprevalence was changing over time, and how those time effects were associated with elk population size and density as of 2006. Wyoming elk population sizes were extracted from annual reports of fixed-wing aerial trend counts (Wyoming Game and Fish Department 2007). We used these trend counts as indices of the elk population to illustrate large differences among regions and time periods that are unlikely to be due to annual variations in observability or changes in the observers over time.

Similar data for the elk brucellosis in Montana were unavailable, but we investigated trends in population sizes and aggregation patterns to assess the future risk of brucellosis transmission and seroprevalence increases in several other areas of the GYE. Elk population size data were taken from fixed-wing aerial surveys conducted in late winter (Hamlin and Ross 2002, Wyoming Game and Fish Department 2007). Wang et al. (2006) found that the variance attributable to sampling error in the Montana trend counts was small relative to the temporal changes. We use these data to illustrate the large changes that have occurred over time in some areas, which are unlikely to be due to observational methods.

Brucella abortus transmission is probably more dependent on local measures of density or group size during the late winter than overall population size because many aborted fetuses or infectious material from live births are scavenged within 24 to 48 hours (Cook et al. 2004, Maichak et al. 2009). So, we investigated group size data from several regions of Montana. Group size surveys were conducted from December to May, and we used only one survey per year for each area. Data from the Wall Creek region of Montana were based on ground surveys, while HUs 360 , 362,314 , and 317 were based on annual fixed-wing aerial counts. Hamlin and Ross (2002) found that the fixedwing and ground counts conducted near the same time were very similar for Wall Creek. We primarily focus on groups that were similar in size to those on the feeding grounds $(>300)$, which are unlikely to be missed.

We conducted quantile regressions of group size to determine if the upper ends of the group size distribution were changing over time (Koenker 2005). In addition, 
we used Lloyd's mean crowding (Lloyd 1967), $c=m+$ $\left(\left[s^{2} / m\right]-1\right)$ to estimate the mean number of elk that each individual elk interacted with, where $m$ is the mean group size and $s$ is the standard deviation of group size. Mean crowding is probably a better index of force of infection than overall density or mean group size. Elk at the National Elk Refuge were fed at three to four different areas while other feeding grounds use only one location at a time. We included data from the National Elk Refuge from 1991 to 2008.

\section{Simulation model}

We created an age-structured model of two interacting elk populations to assess the extent to which dispersal from feeding grounds could explain brucellosis seroprevalence among unfed elk populations around the GYE. To isolate the effects of dispersal, we assumed that there was no brucellosis transmission from bison to elk and that elk did not transmit to one another off of the feeding grounds. This is probably not the case for the National Elk Refuge where bison and elk are in close contact throughout the winter, but we were primarily interested in modeling elk populations outside of the feeding grounds where bison to elk transmission is likely to be either zero or very low (Ferrari and Garrott 2002). We also assumed that population sizes and brucellosis seroprevalence in feeding-ground elk were constant.

Given these assumptions, elk seroprevalence is a function of dispersal rate $(\mu)$, elk population size of the unfed $\left(N_{\text {uf }}\right)$ and fed $\left(N_{\mathrm{f}}\right)$ populations, seroprevalence in fed elk ( $\boldsymbol{\Psi}$, a vector of seroprevalence at different ages), duration of time that elk survive, and the rate that seropositive calves are born to seropositive mothers $(\rho)$, which may result from infection in the birth canal or consumption of infected milk. We restricted our modeling efforts to females because males are not considered important to the transmission of brucellosis (Cheville et al. 1998) and the majority of the seroprevalence data is from females. We assumed that the dispersal rate $(\mu)$ from the feeding grounds to a particular unfed elk population was less than the rate that elk leave that unfed population for any of the neighboring populations. Therefore, we increased emigration rates from the unfed population by a factor $\varepsilon$ relative to $\mu$.

Let $\mathbf{M}$ represent an age-structured Leslie matrix and $\mathbf{Z}(t)$ represent a vector of the total number of seropositive elk of age $i$ in an unfed population at time $t$. The number of seropositive immigrants per year is then $N_{f} \mu \psi \cdot \mathbf{V}$, where $\mathbf{V}$ was a vector of the stable age distribution (as determined by the right eigenvector associated with the dominant eigenvalue of $\mathbf{M}$ (Caswell 2001). We constructed $\mathbf{M}$ using the vital rates in Appendix A and assumed that calves were born in June and had to survive six months prior to being counted in December. Because we were interested in the dynamics of seropositives, only a proportion $\rho$ of these calves were recruited into the seropositive population. No individuals survived past 24 years of age. In the absence of vertical transmission, the vital rate estimates in Appendix A resulted in a stable age distribution that was comparable to empirical estimates (Appendix C: Fig. C2). Individuals lost their seropositive status at a rate of $\gamma$. If the ordering of events is dispersal, loss of seropositive status, survival, and reproduction, then the number of seropositive elk in the unfed population can be represented in matrix form as $\mathbf{Z}(t+1)=\mathbf{M}\left([1-g]\left[(1-\mu \varepsilon) \mathbf{Z}(t)+N_{f} \mu \boldsymbol{\psi} \cdot \mathbf{V}\right]\right)$ and $\Sigma_{i=1}^{24} Z_{i}(t) / N_{\mathrm{uf}}$ is the seroprevalence at time $t$. Initial analyses of the model showed that $\mathbf{Z}(t)$ approached an equilibrium within the first 20 years and only the ratio of elk population sizes $\left(N_{\mathrm{f}}: N_{\mathrm{uf}}\right)$ affected seroprevalence (rather than the total sizes of either population).

To evaluate the sensitivity of the model we randomly chose parameter values for $\mu, \varepsilon, \mathbf{M}, \gamma, \rho, N_{\mathrm{f}}: N_{\mathrm{uf}}$, and $\boldsymbol{\Psi}$ from a uniform distribution ranging from their minimum to maximum values (Appendix A) and calculated the resulting seroprevalence at year 100 (Wisdom et al. 2000, Cross and Beissinger 2001). Because we were interested in the aggregate impact of survival across all ages, rather than within a specific age class, we chose a random number $x$ from a uniform distribution $U(0,1)$ and then scaled all age-specific survival rates $s_{i}$ for the simulation according to $\left[\max \left(s_{i}\right)-\min \left(s_{i}\right)\right] x+\min \left(s_{i}\right)$. We followed a similar procedure for reproductive rates and $\boldsymbol{\Psi}$. We simulated the model with 2000 different parameter sets and then used simple linear regressions to assess the effect of each model parameter on the seroprevalence of brucellosis in the free-ranging population of elk. Visual inspection of the plots did not suggest any nonlinear effects. From each linear regression we assessed the $r^{2}$, slope $(\beta)$, and $\beta / \mathrm{SE}$.

We also used the population model to assess the potential role of shifting age structures as an explanation for the increases in brucellosis seroprevalence. Even though we restricted our statistical analyses to adult elk (2.5 years or older), the adult segment may, on average, be getting older in some herd units, potentially resulting in an increase in seroprevalence. Estimates of adult ages were unavailable for the hunter samples. Therefore, we used the right eigenvector of the Leslie matrix to assess potential shifts in the stable age distribution (Caswell 2001) assuming low and high vital rate estimates (Appendix A). Further, if we assume brucellosis has no effect on survival, serotiters are not lost over time, and a constant infection hazard, then the seroprevalence $S$ of age $a$ equals $1-\exp (-\lambda a)$; see Heisey et al. 2006. Using this relationship we assess the effects of shifting age structures by calculating the average seroprevalence weighted by the stable age distribution. Even though serotiters are likely to wane over time, this would not affect our conclusions if the 


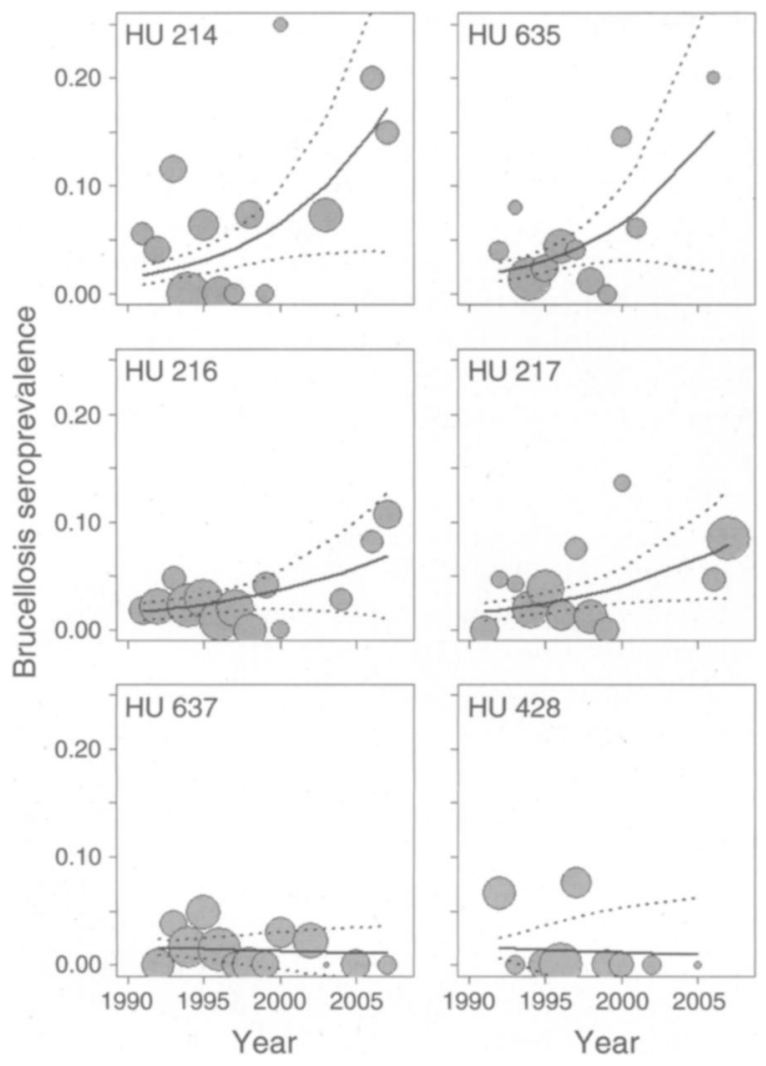

FIG. 2. Seroprevalence (i.e., the proportion of individuals that test positive) of brucellosis (Brucella abortus) in adult female elk from Wyoming herd units (HU). The radius of each point is proportional to the sample size for that year $(37 \pm 32$ [mean \pm SD]). The high SD is due to some years of very large samples (100+), while many years are 10-30 samples. The solid line in each panel is the logistic regression based upon individual-level data, and dotted lines are the normal approximation of the $95 \% \mathrm{CL}$ adjusted for overdispersion.

loss of serostatus is roughly equivalent among age categories.

\section{Model parameter estimates}

We based our survival and reproduction rates (Appendix A) primarily on White et al. (2003), Evans et al. (2006), and Barber-Meyer et al. (2008). Elk vital rates have varied over time in this region, so we simulated a wide range of values. A number of studies have monitored the dispersal patterns of elk in this region (Cole 1969, Smith and Anderson 2001, Hamlin and Ross 2002). Summarizing data from multiple areas around the GYE, Hamlin and Ross (2002) estimated female emigration rates as $0.7-3.8 \%$ and male rates as $3.2-10.9 \%$, while Smith and Anderson (2001) found that none of the 161 juvenile elk that they tracked dispersed outside of the Jackson herd unit. Based on the confidence limits of Smith and Anderson (2001), we assumed a dispersal rate between zero and 0.03 per year.

The relative number of elk on feeding grounds vs. off feeding grounds depends on the unfed elk population of interest. For generality, we simulated over a range of ratios from an equal number in the two populations to five times more elk on the feeding grounds than on native winter ranges. Loss of serostatus $(\gamma)$, vertical transmission $(\rho)$, and the ratio of immigration from the feeding grounds to emigration from the unfed population $(\varepsilon)$ were unknown parameters. We simulated a range of different values for each, and model outcomes were relatively insensitive to these parameters. We conducted the modeling analyses in MATLAB version 7.6 (Mathworks 2007) and the statistical analyses in $R$ version 2.7.0 (R Development Core Team 2005).

\section{RESULTS}

\section{Seroprevalence and population counts}

Brucellosis seroprevalence in several regions around Wyoming has been increasing, particularly since 2000 (Fig. 2). All of the top models included a time effect, while the model with the lowest QAIC allowed each herd unit to have different time effects, but a common intercept (Table 1). Seroprevalence values since 2006 were $0.175(95 \% \mathrm{CL}=0.073,0.327)$ in Gooseberry (HU 214), 0.097 (95\% CL $=0.045,0.175$ ) in Cody (HU 216), and $0.076(95 \% \mathrm{CL}=0.042,0.124)$ in Clark's Fork (HU 217), which is similar to the seroprevalence of hunted elk from feeding-ground herd units (seroprevalence $=0.14$, 95\% $\mathrm{CL}=0.096,0.19$ ). (The preceding statement is supported by Fig. 2, as well as by Scurlock and Edwards, in press.) The top model suggested that herd units $214,216,217$, and 635 were all increasing in seroprevalence since 1991 while 428 and 637 were not (Table 2). These increases roughly corresponded to the 2006 elk population counts in these herd units, with the exception of HU 214 (Figs. 3B and 4A). The Gooseberry HU (214) had a relatively low population size but showed strong increases in seroprevalence. However, when we divided the elk counts by the size of the herd unit, all of the areas with increasing seroprevalence had elk densities higher than $0.4 \mathrm{elk} / \mathrm{km}^{2}$ (Fig. 4B).

We investigated the temporal changes in seroprevalence from HUs with supplemental feeding grounds using both the hunter samples $(N=523,1991-2007)$ collected in the fall and the management captures on the feeding grounds in the spring $(N=2070,1993-2008)$. A logistic regression of the hunter samples did not indicate

TABLE 2. Logistic regression parameter estimates for the model with the lowest QAIC value in Table $1(N=3384)$.

\begin{tabular}{lrrrr}
\hline \hline Parameter & Estimate & SE & \multicolumn{1}{c}{$Z$} & \multicolumn{1}{c}{$P$} \\
\hline (Intercept) & -4.065 & 0.254 & -16.0 & $<0.0001$ \\
Year: HU 214 & 0.156 & 0.036 & 4.3 & $<0.0001$ \\
Year: HU 216 & 0.091 & 0.037 & 2.5 & 0.0130 \\
Year: HU 217 & 0.101 & 0.029 & 3.5 & 0.0005 \\
Year: HU 428 & -0.040 & 0.203 & -0.2 & 0.8444 \\
Year: HU 635 & 0.156 & 0.044 & 3.6 & 0.0003 \\
Year: HU 637 & -0.288 & 0.816 & -0.4 & 0.7241 \\
\hline
\end{tabular}

Notes: Standard errors were adjusted for overdispersion $(\hat{c}=$ 1.8). All herd units (HU) are from Wyoming. 

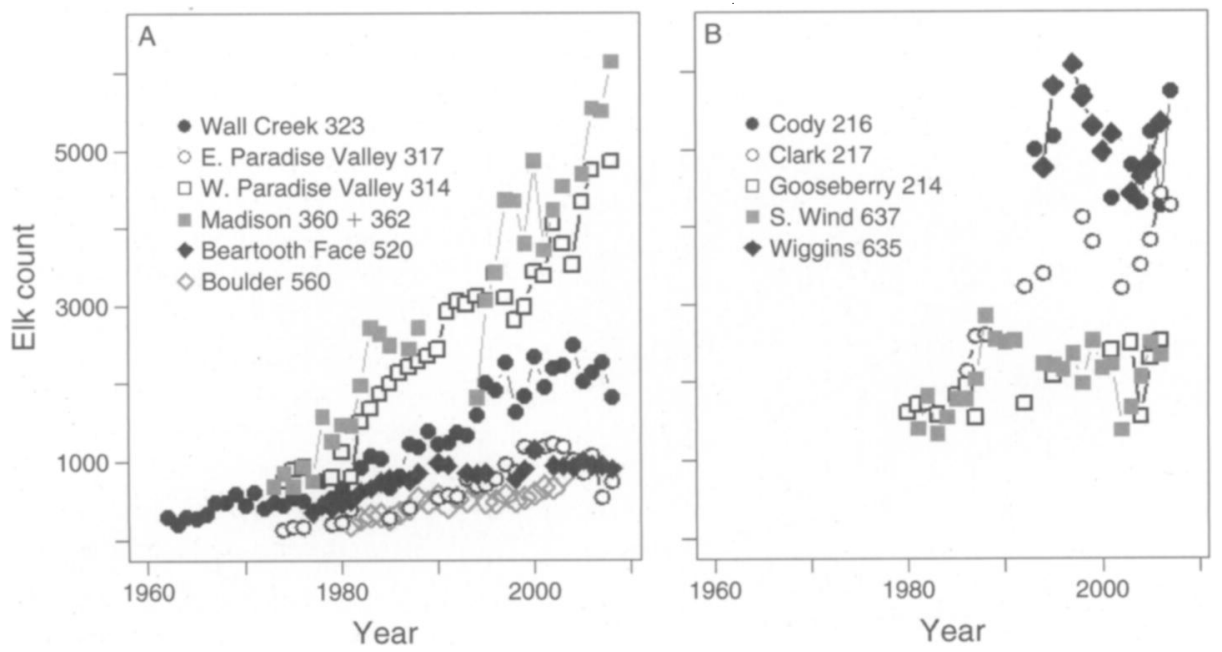

Fig. 3. Elk population counts in herd units of (A) Montana and (B) Wyoming.

that seroprevalence on HUs $100-108$ was significantly increasing, although the slope was positive $\left(\beta_{\text {year }}=0.050\right.$ \pm 0.036 [mean $\pm \mathrm{SE}], P=0.165)$. When conducting the logistic regression of the capture data we incorporated feeding-ground sites as main effects because supplemental feeding grounds varied in their seroprevalence and the sampling intensity varied among feeding grounds over time (Cross et al. 2007). The logistic regressions of the capture data also did not suggest that seroprevalence was increasing on the feeding grounds $\left(\beta_{\text {year }}=0.020 \pm\right.$ $0.014, P=0.169$ ). Finally, elk counts from 1982 to 2007 did not suggest large increases in the number of elk using the feeding grounds. From 1982 to 1987 the number of elk counted on the feeding grounds increased from 17770 to 20145 , but the number was relatively stable for the past 20 years ranging from 20000 to 26000 (Appendix B).

\section{Population model}

Sensitivity analyses of the age-structured population model illustrated that the most important model parameters were dispersal and the ratio of fed to unfed elk population sizes (Appendix C). Survival, reproduction, loss of serostatus $(\gamma)$, and the rate that calves are born seropositive $(\rho)$ all explained $<5 \%$ of the variation in brucellosis seroprevalence (Appendix A). As expected, increasing the dispersal rate from the feeding grounds increased the seroprevalence of unfed populations. Seroprevalence also increased with the ratio of fed to unfed elk due to more dispersers moving into a smaller
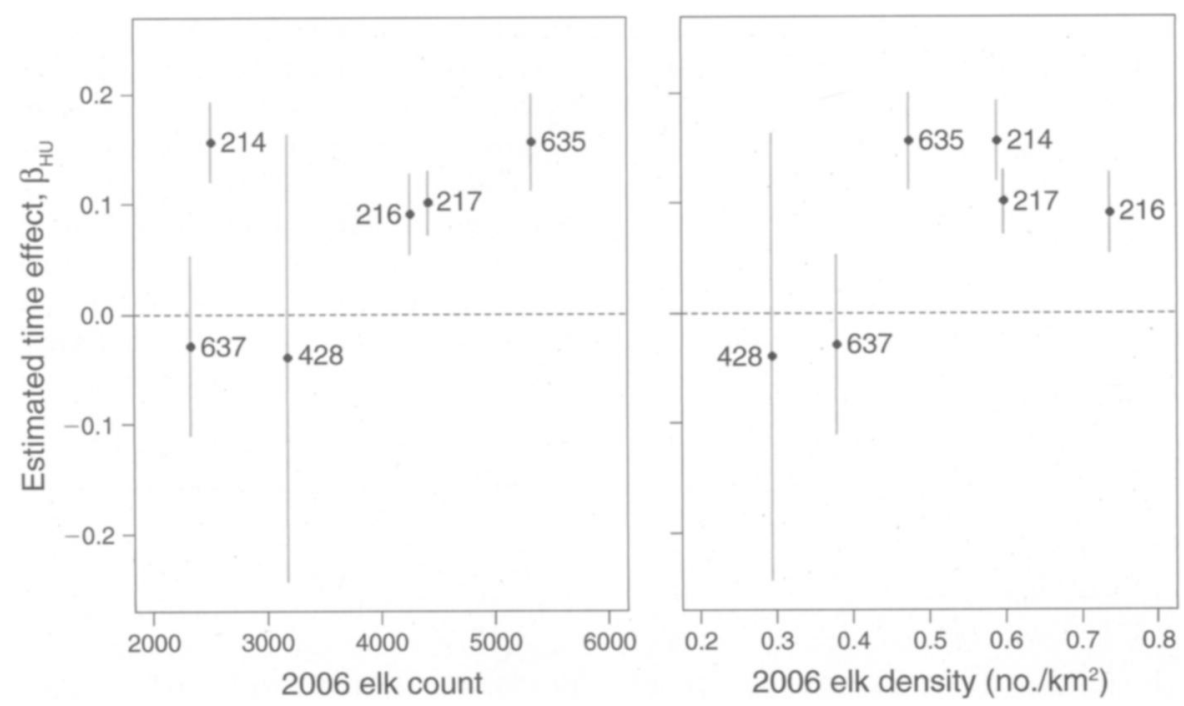

FIG. 4. Estimated year effects ( \pm SE, on the logit scale) for each herd unit (identified by numbers) compared to the count and density of elk in those herd units as of 2006. Estimates were based on the top logistic regression model (Table 1) using the serological results of adult female elk from non-feeding-ground herd units $(N=3384)$. Standard errors were adjusted to account for overdispersion. 


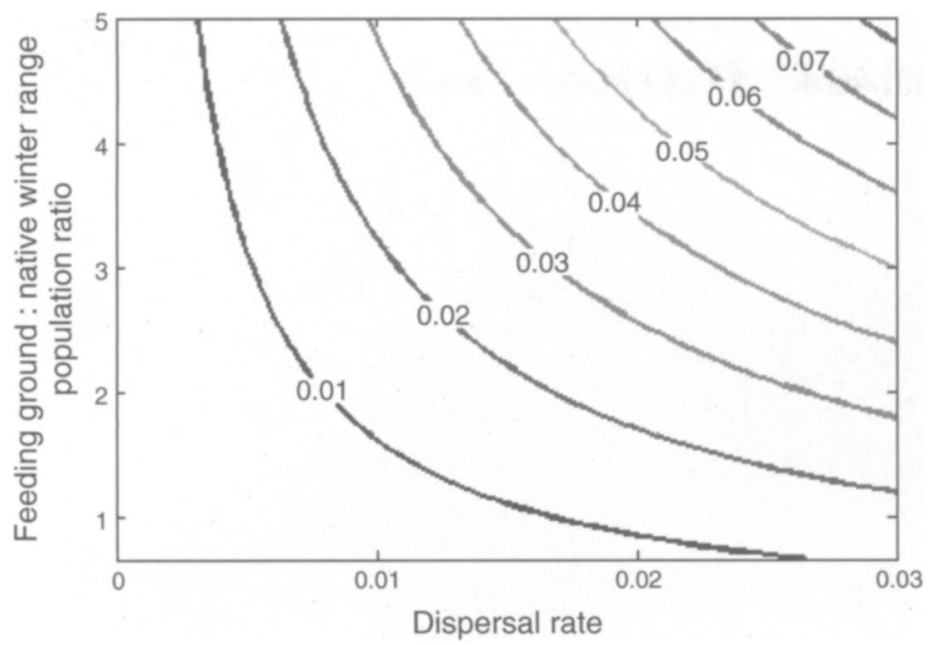

FIG. 5. Contour plot of simulated brucellosis seroprevalence values for native winter range elk, given a range of annual dispersal rates and a ratio of elk population sizes from one to five times as many elk on feeding grounds compared to native winter range. Simulations used the baseline parameter values in Appendix A. population of unfed elk. Despite the importance of dispersal to model results, even dispersal rates of $3 \%$ per annum and five times more fed than unfed elk translated to a seroprevalence off of the feeding grounds of $<10 \%$ (Fig. 5). For the parameter ranges we explored, dispersal rates $<0.01$ per year seldom resulted in a seroprevalence in unfed elk higher than 3\% (Appendix C).

To assess the effects of changing age structures on our adult seroprevalence we used the Leslie matrix $\mathbf{M}$ to estimate the stable age distributions given the low and high vital rates in Appendix A. Assuming vital rates at the upper bounds in Appendix A, the age distribution shifts toward younger age classes and the average age of individuals over 2 years old is 7.1 years old (Appendix C). The age distribution shifts towards older age classes and the average age of adults is 11.6 years old if vital rates are set to the lower bounds. A constant annual force of infection $\lambda$ of 0.005 would result in a seroprevalence of $1.5 \%$ and $9.5 \%$ in 3-yr-old and 20 yr-old elk, respectively. However, given the age distributions in Appendix C, this translates to a minor change in the average adult seroprevalence of $3.5 \%$ to $5.6 \%$ for high and low vital rates, respectively.

\section{DisCUSSION}

The recovery of North American elk populations from the over harvesting and land conversion of the early 20th century has been a tremendous success for conservationists. The resulting increase in population size, however, presents managers with a new suite of issues (e.g., private property damage, crop depredation, vehicle collisions, hunter access, and disease). For many years the $50 \%$ seroprevalence of brucellosis in bison, 10 $30 \%$ seroprevalence in feeding-ground elk, and 2-3\% seroprevalence in unfed elk populations of the GYE seemed relatively constant. Since 2000 , however, brucellosis seroprevalence has been increasing in several elk populations of Wyoming (Fig. 2). These increases in seroprevalence roughly corresponded to the density of elk in those herd units (HUs). The data did not suggest that either the number or seroprevalence of elk from the feeding-ground areas of Wyoming were increasing. Some regions with increases were relatively distant from the feeding grounds (e.g., HU 214, 216, 217) while HUs 637 and 428 showed no increase and are adjacent to the feeding-ground herd units (Figs. 1 and 2). Further, our analyses of an age-structured population model indicated that dispersal rates or changes in the age structure of the elk populations would have to be unrealistically high to account for large increases in brucellosis seroprevalence (Fig. 5).

There are at least two other possible explanations for the detected increases in brucellosis seroprevalence. First, they could be due to cross reactions with another pathogen, such as Yersinia enterocolitica, that shares the major $O$-polysaccharide (OPS) with $B$. abortus (Caroff et al. 1984, Gourdon et al. 1999). However, Nielsen et al. (2004) noted that very few cattle infected with $Y$. enterocolitica $0: 9$ were positive based on fluorescence polarization assay (FPA) or cELISA. In addition, the hypothesized Yersinia spp. outbreak would need to be occurring across many regions of the GYE since 2000, but not in the rest of Wyoming where no brucellosis seropositives have been found from 1426 samples (Scurlock and Edwards, in press). Additional testing for $Y$. enterocolitica is underway. Another explanation could be increased transmission from bison to elk. Ferrari and Garrott (2002), however, found no correlation between the seroprevalence in elk and bison, indicating that intraspecific transmission may be rare. In addition, elk herd units with the strongest increases in seroprevalence (HU 214 and 635) were not adjacent to areas with bison.

If elk population densities are driving the observed increases in brucellosis seroprevalence in Wyoming, then this finding has important implications for neighboring elk populations in Montana and Idaho. The abundance of many elk populations in the GYE has increased over the past $30-50$ years (Fig. 3), with the exception of those in the central and northern region of YNP (Appendix B; 
see also Garrott et al. 2005, Eberhardt et al. 2007). In particular, there were five to nine times more elk in the western Paradise (HU 314) and eastern Madison valleys (HU 360 and 362) of Montana during 2008 than there were in 1975 (Fig. 3A). Median and mean winter group sizes for unfed Montana elk were relatively small ( 9 and 50, respectively; Fig. 6; Appendix D). However, there were a number of large groups comparable to the feeding grounds and the number of large groups increased over time in some areas (Fig. 6; Appendix D). Quantile regression analyses indicated that the upper ends of the elk group size distributions have been increasing over time in both the eastern Madison and western Paradise valleys (Appendix D). In 2008, at least 10 groups with more than 300 elk were observed in four populations on the Montana side of the GYE. This translated into a Lloyd's mean crowding (Lloyd 1967) of elk in the eastern Madison valley of Montana that was similar to that of elk on Wyoming feeding grounds (Fig. 6C).

We believe these elk aggregations are a risk factor for future increases in brucellosis, as well as the introduction of other diseases. When elk populations were small, brucellosis may not have been able to invade and persist in most free-ranging elk populations, and the low seroprevalence of elk may have been due to seropositive, but non-infectious, elk. At that time, management intended to eradicate brucellosis from the GYE could have focused only on the supplemental elk feeding grounds and the bison populations of Yellowstone and Grand Teton National Parks. Several Wyoming elk populations now appear to be maintaining brucellosis in areas far from supplemental feeding grounds and bison. A similar dynamic may occur in Montana (Fig. 6; Appendix D). Persistence of brucellosis in free-ranging elk means that the current focus on feeding grounds and bison is probably insufficient for eradication or even controlling the risk of transmission to cattle. Freeranging elk populations and, in particular, the large winter and spring aggregations of elk should be considered in future management strategies.

The hypotheses we address in this paper are not mutually exclusive and some combination of factors may be operating. Our modeling analyses suggest that altered age structure or dispersal has minor effects on seroprevalence. However, several mechanisms could plausibly explain the low seroprevalence (e.g., $<5 \%$ ) of some areas like the Yellowstone National Park (BarberMeyer et al. 2007). If dispersal rates from the feeding grounds are on the order of one in every 100-200 individuals per year, then these rare dispersal events may be sufficient to maintain the seroprevalence of brucellosis at $2 \%$ without any subsequent transmission. We note, however, that in this region a similar argument could be made for the transmission of brucellosis from bison to elk. Our model predicts that in a population of 6000 elk only $35-40$ seropositive elk would need to enter the population per year for a seroprevalence of $2 \%$. Those seropositive elk could be immigrants or they
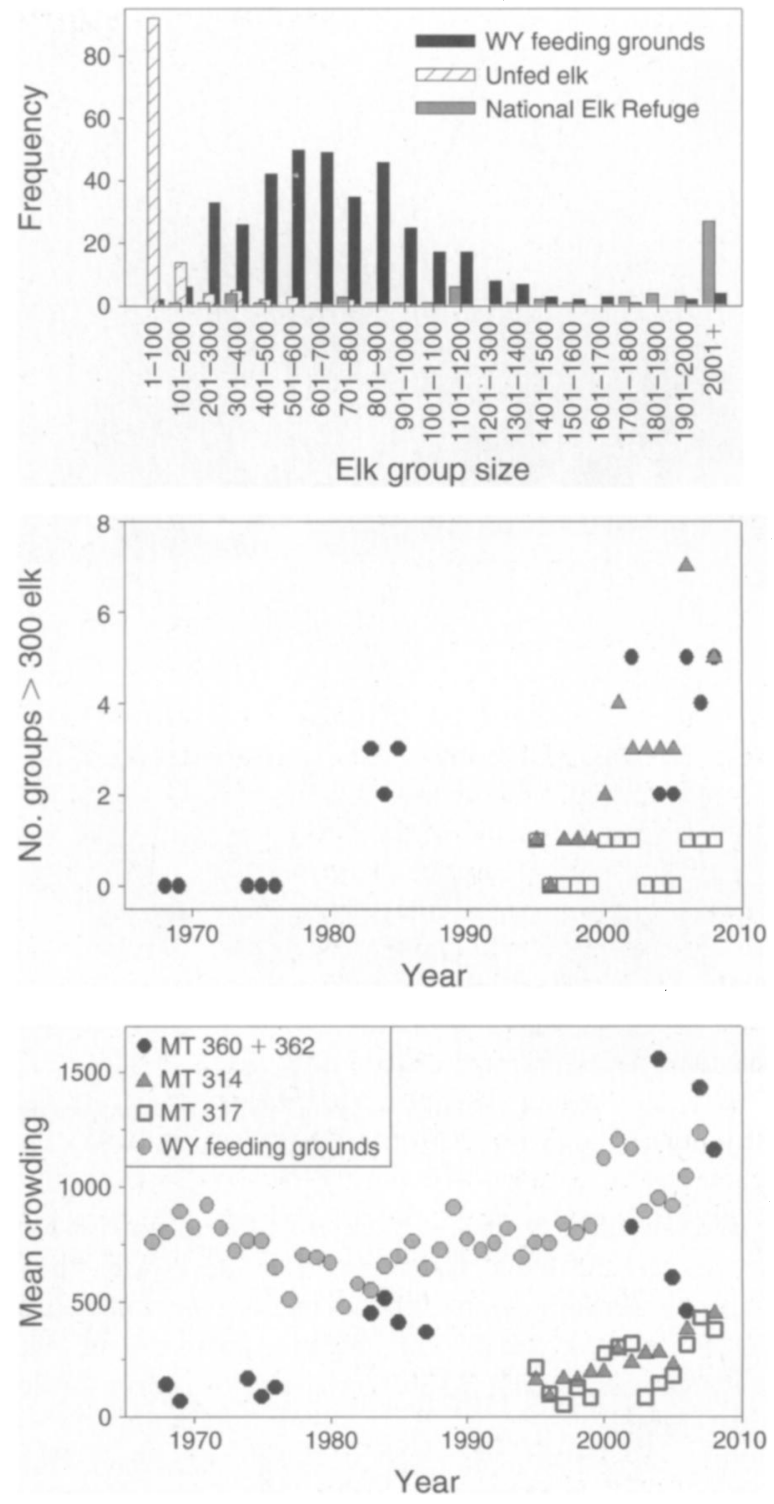

FIG. 6. (Top) Comparisons of elk group size distributions using histograms; (middle) total number of groups with $>300$ elk; and (bottom) mean crowding (i.e., the expected group size of a randomly chosen individual. Data for the top panel.were taken from 2006 for Montana elk in herd units 314, 317, 360, and 362 , and from 1990 to 2007 for the feeding grounds. The National Elk Refuge is not included in the bottom panel.

could have acquired the infection from nearby herds of bison.

The distinction between dispersal and active on-site transmission is important for the determination of risk to surrounding cattle operations, as well as the effectiveness of future management strategies. Elk are probably only infectious for the one to two years after infection (Thorne et al. 1978a, b). Thus, if elk disperse after that time, they may be seropositive but not infectious. Therefore, if dispersal alone is responsible for sustaining a low seroprevalence of brucellosis on a 


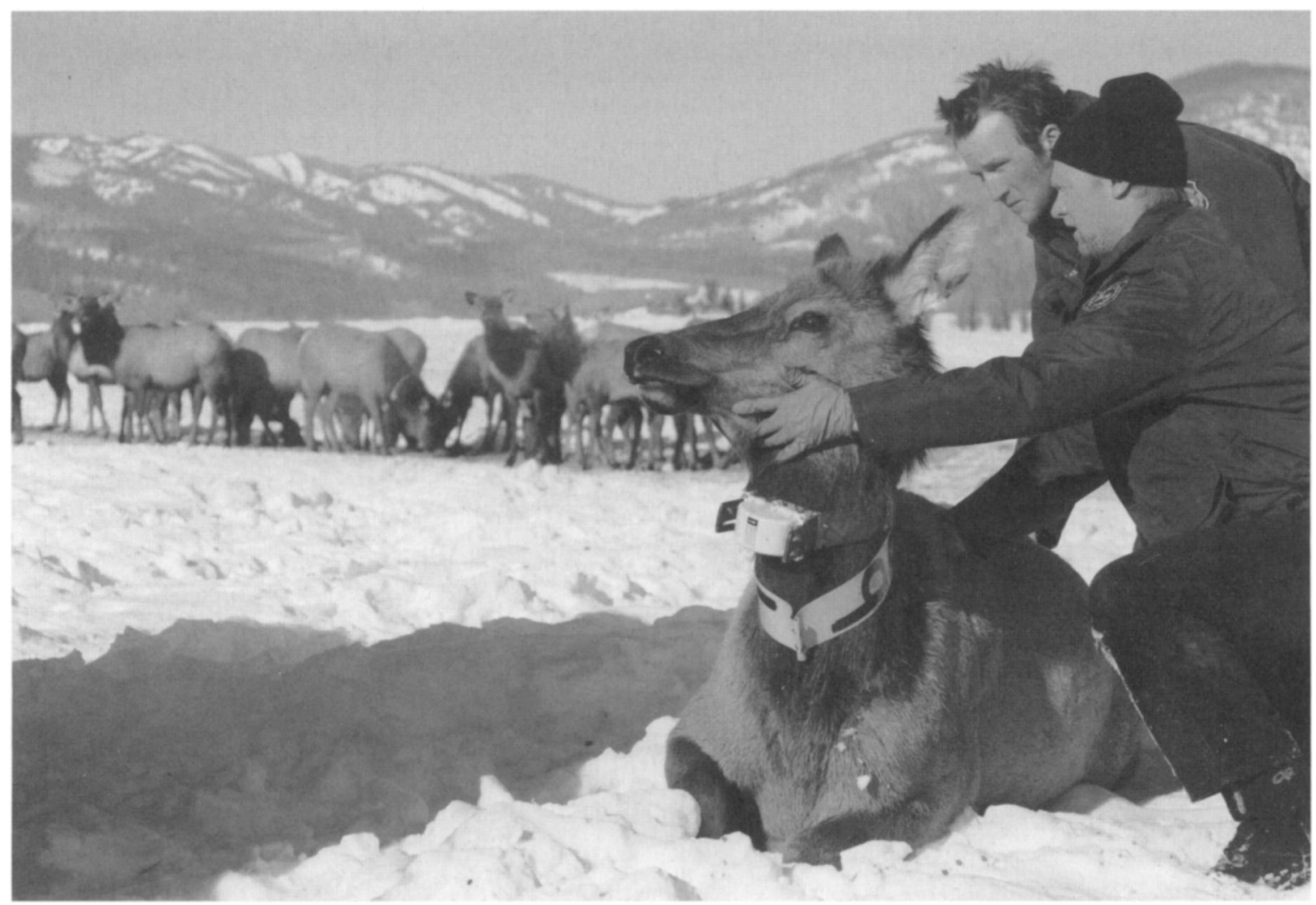

Plate. 1. Wyoming Game and Fish (WGFD) employees place a Global Positioning System (GPS) collar on an elk at the South Park feeding ground outside of Jackson, Wyoming (USA). Photo credit: Mark Gocke (WGFD).

given site, the elk may still present little to no risk for cattle. If elk-to-elk transmission is occurring, then seroprevalence may continue to increase on some sites as $B$. abortus tracks the changing patterns of elk aggregations, posing a substantial risk to nearby cattle operations.

We suggest several lines of research to refine (or refute) our conclusions. First, genetic analyses of brucellosis strains from bison, elk, and cattle may help to assess the amount of transmission within and among host species in the different regions. Second, understanding what factors contribute to the creation of very large elk groups will be critical to developing effective management strategies. For example, Haggerty and Travis (2006) found that changes in land ownership from livestock production to owners interested in natural amenities may lead to elk populations that are "out of administrative control" due to a lack of hunter access. In addition, large predators (grizzly bears, mountain lions, and wolves) are a potentially effective means of disease management and prevention. Predators may reduce elk numbers and target aggregations that are inaccessible to hunting pressure, but predators also present risks to livestock and landowners. The effects of wolves on elk group sizes appear to depend upon habitat type (Creel and Winnie 2005, Gude et al. 2006, Winnie and Creel 2007, Gower et al. 2009). Additional work on how brucellosis seroprevalence relates to elk group size distributions and the effects of predators on the largest elk groups (e.g., $>300$ ) is needed. Finally, hierarchical statistical models implemented at finer spatial scales could help to determine the relative roles of local elk density, group size distribution, land use, habitat type, and proximity to the feeding grounds on brucellosis seroprevalence.

The recent outbreaks of brucellosis in cattle from Montana, Idaho, and Wyoming have redirected some of the management focus from bison to elk. One proposal is to reduce overall elk numbers through increased hunting, but hunter access to dense aggregations of elk is often limited by private landowners or land managers (Haggerty and Travis 2006). In these cases, increased license sales and hunting may reduce elk populations overall, yet fail to impact large groups on private refuges. Indeed, in several regions in Montana where populations have increased dramatically (HD 314, 360, and 362), the number of harvested female and calf elk has been relatively constant or decreasing despite increasing permit levels and regulations since 2004 that allow season-long antlerless elk harvests to any hunter. Without the enhanced cooperation of private landown- 
ers, it will be difficult to reduce elk populations in the most risky areas.

\section{ACKNOWLEDGMENTS}

We thank the Wyoming Game and Fish Department for providing elk serology data spanning decades of hard work. Idaho Fish and Game provided data from the Sand Creek region. K. Hamlin organized elk data from Montana contributed by B. Brannon, C. Jourdonnais, F. King, T. Lemke, J. Paugh, and S. Stewart. WGFD, USGS, and USFWS provided funding for the study. K. Lafferty, E. Osnas, J. Cunningham, D. McWhirter, and several anonymous reviewers provided helpful comments on earlier drafts. The views and opinions in this article are those of the authors and should not be construed to represent any views, determinations, or policies of the U.S. Government. Also, any use of trade, product, or firm names is for descriptive purposes only and does not imply endorsement by the U.S. Government.

\section{Literature Cited}

Animal Plant Health Inspection Service. 2003. Brucellosis in Cervidae: Uniform methods and rules, United States Department of Agriculture. Report \# 91-45-013. (http:// www.aphis.usda.gov/animal_health/animal_diseases/ brucellosis/downloads/bcervumr.pdf)

Barber-Meyer, S. M., L. D. Mech, and P. J. White. 2008. Elk calf survival and mortality following wolf restoration to Yellowstone National Park. Wildlife Monographs 169:1-30.

Barber-Meyer, S. M., P. J. White, and L. D. Mech. 2007. Survey of selected pathogens and blood parameters of northern Yellowstone elk: wolf sanitation effect implications. American Midland Naturalist 158:369-381.

Bendixen, H. C., and E. Blom. 1947. Investigations on brucellosis in the bovine male, with special regard to spread of the disease by artificial insemination. Veterinary Journal 103:337-345

Burnham, K. D., and D. R. Anderson. 2002. Model selection and multimodel inference: a practical information-theoretic approach. Second edition. Springer-Verlag, New York, New York, USA.

Caroff, M., D. R. Bundle, and M. B. Perry. 1984. Structure of the O-chain of the phenol-phase soluble cellular lipopolysaccharide of Yersinia enterocolitica O:9. European Journal of Biochemistry 139:195-200.

Caswell, H. 2001. Matrix population models: construction, analysis, and interpretation. Second edition. Sinauer Associates, Sunderland, Massachusetts, USA.

Cheville, N. F., D. R. McCullough, and L. R. Paulson. 1998. Brucellosis in the Greater Yellowstone Area. National Academy Press, Washington, D.C., USA

Cole, G. F. 1969. The elk of Grand Teton and southern Yellowstone National Parks. Research Report GRTE-N-1, and manuscript for Fauna of the National Parks of the United States. U.S. National Park Service, Office of Natural Science Studies, Washington, D.C., USA.

Cook, W. E., E. S. Williams, and S. A. Dubay. 2004. Disappearance of bovine fetuses in northwestern Wyoming. Wildlife Society Bulletin 32:254-259.

Creel, S., and J. A. Winnie. 2005. Responses of elk herd size to fine-scale spatial and temporal variation in the risk of predation by wolves. Animal Behaviour 69:1181-1189.

Cross, P. C., and S. R. Beissinger. 2001. Using logistic regression to analyze the sensitivity of PVA models: a comparison of methods based on African wild dog models. Conservation Biology 15:1335-1346.

Cross, P. C., W. H. Edwards, B. M. Scurlock, E. J. Maichak, and J. D. Rogerson. 2007. Effects of management and climate on elk brucellosis in the Greater Yellowstone Ecosystem. Ecological Applications 17:957-964.
Eberhardt, L. L., P. J. White, R. A. Garrott, and D. B Houston. 2007. A seventy-year history of trends in Yellowstone's northern elk herd. Journal of Wildlife Management 71:594-602.

Evans, S. B., L. D. Mech, P. J. White, and G. A. Sargeant. 2006. Survival of adult female elk in Yellowstone following wolf restoration. Journal of Wildlife Management 70:13721378 .

Ferrari, M. J., and R. A. Garrott. 2002. Bison and elk: brucellosis seroprevalence on a shared winter range. Journal of Wildlife Management 66:1246-1254.

Garrott, R. A., J. A. Gude, E. J. Bergmann, C. Gower, P. J. White, and K. L. Hamlin. 2005. Generalizing wolf effects across the Greater Yellowstone Area: a cautionary note. Wildlife Society Bulletin 33:1245-1255.

Gelman, A., and J. Hill. 2007. Data analysis using regression and multilevel/hierarchical models. Cambridge University Press, Cambridge, UK

Godfroid, J., and A. Kasbohrer. 2002. Brucellosis in the European Union and Norway at the turn of the twenty-first century. Veterinary Microbiology 90:135-145.

Gortázar, C., P. Acevedo, F. Ruiz-Fons, and J. Vicente. 2006. Disease risks and overabundance of game species. European Journal of Wildlife Research 52:81-87.

Gourdon, F., J. Beytout, A. Reynaud, J. Romaszko, D. Perre, P. Theodore, H. Soubelet, and J. Sirot. 1999. Human and animal epidemic of Yersinia enterocolitica O:9, 1989-1997, Auvergne, France. Emerging Infectious Diseases 5:719-721.

Gower, C. N., R. A. Garrott, P. J. White, S. Cherry, and N. G. Yoccoz. 2009. Elk group size and wolf predation: a flexible strategy when faced with variable risk. Pages 401-422 in R. A. Garrott, P. J. White, and F. Watson, editors. The ecology of large mammals in Central Yellowstone-sixteen years of integrated field studies. Academic Press, San Diego, California, USA

Gude, J. A., R. A. Garrott, J. J. Borkowski, and F. King. 2006. Prey risk allocation in a grazing ecosystem. Ecological Applications 16:285-298.

Haggerty, J. H., and W. R. Travis. 2006. Out of administrative control: absentee owners, resident elk and the shifting nature of wildlife management in southwestern Montana. Geoforum 37:816-830.

Hamlin, K. L., and M. S. Ross. 2002. Effects of hunting regulation changes on elk and hunters in the GravellySnowcrest Mountains. Montana Fish, Wildlife and Parks, Wildlife Division, Helena, Montana, USA.

Heisey, D. M., D. O. Joly, and F. Messier. 2006. The fitting of general force-of-infection models to wildlife disease prevalence data. Ecology 87:2356-2365.

King, R. O. C. 1940. Brucella infection in the bull: a progress report of mating experiences with naturally infected bulls. Australian Veterinary Journal 16:117-119.

Koenker, R. W. 2005. Quantile regression. Cambridge University Press, Cambridge, UK.

Lloyd-Smith, J. O., P. C. Cross, C. J. Briggs, M. Daugherty, W. M. Getz, J. Latto, M. S. Sanchez, A. B. Smith, and A. Swei. 2005. Should we expect population thresholds for wildlife disease? Trends in Ecology and Evolution 20:511519.

Lloyd, M. 1967. Mean crowding. Journal of Animal Ecology $36: 1-30$.

Lubbenhusin, R. E., and C. P. Fitch. 1926. A report on experimental work on the bull as a factor in the spread of infectious abortion. Journal of the American Veterinary Medical Association 69:467-481.

Maichak, E. J., B. M. Scurlock, J. D. Rogerson, L. L. Meadows, A. E. Barbknecht, W. H. Edwards, and P. C. Cross. 2009. Effects of management, behavior, and scavenging on risk of brucellosis transmission in elk of western Wyoming. Journal of Wildlife Diseases 45(2):398-410.

Mathworks. 2007. MATLAB. Natwick, Massachusetts USA. 
McCallum, H., N. Barlow, and J. Hone. 2001. How should pathogen transmission be modelled? Trends in Ecology and Evolution 16:295-300.

Meagher, M., and M. E. Meyer. 1994. On the origin of brucellosis in Bison of Yellowstone National Park-a review. Conservation Biology 8:645-653.

Meyer, M. E., and M. Meagher. 1995. Brucellosis in freeranging Bison (Bison bison) in Yellowstone National Park, Grand Teton National Park, and Wood Buffalo National Parks: a review. Journal of Wildlife Diseases 31:579-598.

Nielsen, K., P. Smith, J. Widdison, D. Gall, L. Kelly, W. Kelly, and P. Nicoletti. 2004. Serological relationship between cattle exposed to Brucella abortus, Yersinia enterocolitica O:9 and Escherichia coli O157:H7. Veterinary Microbiology 100:2530 .

Pappas, G., P. Papadimitriou, N. Akritidis, L. Christou, and E. V. Tsianos. 2006. The new global map of human brucellosis. Lancet Infectious Diseases 6:91-99.

R Development Core Team. 2005. R: a language and environment for statistical computing. $\mathbf{R}$ Foundation for Statistical Computing, Vienna, Austria.

Robison, C. D. 1994. Conservation of germplasm from Brucella abortus-infected bison (Bison bison) using natural service, embryo transfer, and in vitro maturation/in vitro fertilization. Thesis. Texas A\&M University, College Station, Texas, USA.

Roffe, T. J., L. C. Jones, K. Coffin, M. L. Drew, S. J. Sweeney, S. D. Hagius, P. H. Elzer, and D. Davis. 2004. Efficacy of single calfhood vaccination of elk with Brucella abortus strain 19. Journal of Wildlife Management 68:830-836.

Scurlock, B. M., and W. H. Edwards. In press. Status of brucellosis in free ranging elk and bison in Wyoming. Journal of Wildlife Diseases.

Smith, B. L. 2001. Winter feeding of elk in western North America. Journal of Wildlife Management 65:173-190.
Smith, B. L., and S. H. Anderson. 2001. Does dispersal help regulate the Jackson elk herd? Wildlife Society Bulletin 29: $331-341$.

Thomsen, A. 1943. Does the bull spread infectious abortion in cattle? Experimental studies from 1936 to 1942. Journal of Comparative Pathology and Therapy 53:199-211.

Thorne, E. T., J. K. Morton, F. M. Blunt, and H. A. Dawson. 1978a. Brucellosis in elk. 2. Clinical effects and means of transmission as determined through artificial infections. Journal of Wildlife Diseases 14:280-291.

Thorne, E. T., J. K. Morton, and G. M. Thomas. $1978 b$. Brucellosis in elk. 1. Serologic and bacteriologic survey in Wyoming. Journal of Wildlife Diseases 14:74-81.

U.S. Department of Agriculture. 2008. United States achieves cattle brucellosis class-free status. Washington, D.C., USA.

Van Houten, C. K., E. L. Belden, T. J. Kreeger, E. S. Williams, W. H. Edwards, E. T. Thorne, W. E. Cook, and K. W. Mills. 2003. Validation of a Brucella abortus competitive enzymelinked immunosorbent assay for use in Rocky Mountain elk (Cervus elaphus nelsoni). Journal of Wildlife Diseases 39:316322.

Wang, G., N. T. Hobbs, R. B. Boone, A. W. Illius, I. J. Gordon, J. E. Gross, and K. L. Hamlin. 2006. Spatial and temporal variability modify density dependence in populations of large herbivores. Ecology 87:95-102.

White, P. J., R. A. Garrott, and L. L. Eberhardt. 2003. Evaluating the consequences of wolf recovery on northern Yellowstone elk. National Park Service, Yellowstone National Park, Gardiner, Montana, USA.

Winnie, J., and S. Creel. 2007. Sex-specific behavioural responses of elk to spatial and temporal variation in the threat of wolf predation. Animal Behaviour 73:215-225.

Wisdom, M. J., L. S. Mills, and D. F. Doak. 2000. Life-stage simulation analysis: estimating vital-rate effects on population growth for conservation. Ecology 81:628-641.

Wyoming Game and Fish Department. 2007. Annual big game herd unit job completion reports. Cheyenne, Wyoming, USA.

\section{APPENDIX A}

Parameter values and results of the sensitivity analysis of the elk brucellosis model (Ecological Archives A020-005-A1).

\section{APPENDIX B}

Number of elk counted on the Northern Range of Yellowstone National Park, just north of the park, and on the Wyoming supplemental feeding grounds (Ecological Archives A020-005-A2)

\section{APPENDIX C}

Graphs showing simulated brucellosis seroprevalence in native winter range elk under a range of different parameter values and a comparison of empirical and simulated elk age distributions (Ecological Archives A020-005-A3).

\section{APPENDIX D}

Boxplots of elk group sizes over time around the Greater Yellowstone Ecosystem and elk group sizes for Montana hunt districts 360, 362, and 314 (Ecological Archives A020-005-A4). 